\title{
Determining the Relationship between Sleep and Social Activity in Community Dwelling Older Individuals
}

\author{
J. Behan, D. Prendergast, B. Quigley, L. Walsh
}

\begin{abstract}
This paper describes a preliminary study carried out by the Digital Health Group in Intel with an aim to examine daily social rhythms within community dwelling seniors and their relation to objectively and subjectively recorded sleep. Sensing elements were placed in the homes of 10 relatively healthy senior participants for a period of two weeks to monitor sleep and specific social activities including mobility and contact with others.
\end{abstract}

\section{INTRODUCTION}

$\mathrm{I}$ sleep the new vital sign? Much like nutrition and exercise the issue of sleeplessness is emerging as an important aspect of health promotion and disease prevention. Research has shown that more than half of all adults aged over 65 have suffered from at least one sleep complaint and approximately one third report sleep maintenance insomnia or early morning awakening [1]. Elderly people rate sleep concerns as one of their top ten health problems, but they typically view these problems as just a part of normal ageing [2]. There is much theoretical interest focused on the nature of sleep in older persons. It may be that specific forms of temporal instabilities, i.e. inconsistencies over time, in sleep patterns of the elderly are associated with risk of morbidity or mortality. The central controls for sleep are diminished in both the very young and the very old. Even though the mechanisms may differ, those elderly who are less stable in their sleep characteristics over time may have subtle central nervous systems dysfunction, which makes them more vulnerable to physiological or environmental stress [3]. However, whilst some have pointed out the links between sleep disturbance in older people and the deterioration of the circadian timing system [4], there is a growing body of research that suggests that this is not an inevitable consequence of ageing but should be considered in relation to a range of factors including life events, chronic disease, physical disability, depression, widowhood, medication, and social activity. Foley et al. suggests that sleep problems are secondary to medical illness rather than ageing per se particularly heart disease, depression, arthritis and obesity [5]. Ohayon et

Manuscript received January 25, 2008.

J. Behan is a health research technologist within the Product Research and Incubation (PRI) Group of the Digital Health Group, Intel Ireland, Leixlip, Co-Kildare, Ireland (00353 1 6062935; e-mail: Julie.Behan@intel.com).

D. Prendergast is a senior ethnographer with the PRI Group of the Digital Health Group at Intel Ireland

B. Quigley is a Ph.D. intern student with the PRI Group of the Digital Health Group at Intel Ireland

L. Walsh is a Ph.D. candidate with the Department of Electronic Engineering at the National University of Ireland, Maynooth, Ireland. al. [6], suggest that amongst retirees continuing engagement in social life coupled with curtailing time in bed is associated with preservation of better sleep quality. Gooneratne et al. [7] used the Functional Outcomes of Sleep Questionnaire to measure functional areas sensitive to sleep disturbances in adults. They found that sleepiness had a moderate to large negative effect size on the following domains of the scale: social outcomes $=0.65$; general productivity $=0.59$; vigilance $=0.75$; and activity level $=0.83$ (all $P$ values $<0.005$ ). In a sleep study of 1506 community dwelling healthy older participants Chasens et. al [8] showed that increasing age was not strongly associated with the frequency of sleep disturbances (symptoms of restless leg syndrome, insomnia, OSA) or with the frequency of daytime sleepiness but that sleepiness in the elderly may be associated with de-conditioning and declines in physical functioning. Existing laboratory and field studies of elderly subjects' circadian rhythms have indicated a lower amplitude, which could be indicative of failures in the entertainment process needed to keep rhythms synchronized and on track [9]. The argument that many of the health changes in later life, including the decline in sleep and cognitive abilities, can be minimized by avoidance of social isolation and disengagement is supported by Benloucif et al. [10]. These authors found that regular physical and social activity can improve objective neuropsychological performance and subjective sleep quality in older adults. Similarly, a study by Shirota et al. [11] in Japan suggests that a high volitional lifestyle, particularly with more time spent in mental activities, may contribute to a good nocturnal sleep among older people. Problems of sleep timing for the elderly are often exacerbated by the absence of work or social commitments leading to the feeling that "there's nothing worth getting up for". Thus boredom and loneliness can lead to a day that is not only unfilled but also unstructured, thereby worsening the circadian dysfunction and hence the sleep problems experienced [12].

This paper describes a preliminary study carried out by the Product Research and Incubation Group within the Digital Health Group in Intel with an aim to examine daily social rhythms in community dwelling seniors as they followed their usual schedule of activities, rest and sleep throughout the day and night, recorded both objectively and subjectively. The study focus was to examine the relationship between social activities and sleeping behaviours and to determine the interrelationship between daytime and nocturnal routines. 


\section{METHODS}

Ten independently living older adults were recruited from a focus group in a rural village in Co. Meath in Ireland. A pre-trial ethnographic interview was held in the home of each participant to broadly identify perceived lifestyle patterns, social, physical, mental and leisure activities, networks, nocturnal habits, etc. A network of sensors was placed in each household for a period of two weeks. Sociality behaviours were explored through social contact both through phone conversation and human interaction, through mobility, inside and outside the home, and through a person's self reported internal state. The sensing elements included a Tactex BEDsensor ${ }^{\mathrm{TM}}$ under mattress bed pressure sensor, an actigraph watch, caller-id logging on landline telephones, which monitored time, direction and duration of each call. Pedometers and personal and automobile GPS tracker devices were used to monitor mobility both inside and outside the home. Daily morning and evening diaries were completed by the participant through digital audio recorders. These diary entries consisted of a suitably modified version of the Pittsburg sleep diary to allow manual twice daily logging of relevant data, in an audio form, following procedures developed for the qualitative study of sleep by Hislop et al. [13]. The person's self reported internal state (how they feel each day) was also recorded daily. A mid trial visit occurred at the end of week one, and further ethnographic interviews were conducted at the end of the trial. The ethnographic interviews were used to establish routine behaviours and used to validate discrepancies within sensor data.

\section{NOCTURNAL ROUTINE MONITORING}

A quality of sleep measure was extracted for each participant using a measurement of primary patterns including: bed entry and exit times, time in bed (TIB), number and duration of bed exits during the night, restlessness patterns established through an index of restlessness and percentage of restlessness measures. The sleep data was correlated and extracted using a Tactex BEDsensor ${ }^{\mathrm{TM}}$, under mattress bed pressure sensor. The Tactex BEDsensor ${ }^{\mathrm{TM}}$, bed sensor permits 24-hour monitoring of sleep whenever subjects are in bed. The sensor data is autonomously logged through a PDA (Dell Axim x51v), which was stored underneath the bed. Table 1 displays the parameters extracted from both the Tactex BEDsensor ${ }^{\mathrm{TM}}$ and actigraph watch for each individual study participant and Table 2 displays the mean parameters obtained for the duration of the study.

TABLE 1: SLEEP PARAMETERS OF STUDY PARTICIPANTS

\begin{tabular}{|c|c|c|c|c|c|c|c|c|c|}
\hline Subject & Sex & Age & $\begin{array}{l}\text { Health } \\
\text { Record }\end{array}$ & TIB* & $\begin{array}{c}\text { Actual } \\
\text { Sleep Time }\end{array}$ & $\begin{array}{c}\text { Sleep } \\
\text { Efficiency }\end{array}$ & $\begin{array}{l}\text { Sleep } \\
\text { latency }\end{array}$ & $\begin{array}{c}\text { No. of } \\
\text { bed exits } *\end{array}$ & $\begin{array}{c}\% \\
\text { Restlessness * }\end{array}$ \\
\hline DH701 & $\mathrm{F}$ & 63 & $\begin{array}{l}\text { Sleep } \\
\text { Apnea }\end{array}$ & $9: 30: 19$ & $6: 38: 07$ & $70.15 \%$ & $0: 52: 56$ & 3.93 & $19 \%$ \\
\hline DH702 & $\mathrm{F}$ & 79 & $\begin{array}{l}\text { Spina } \\
\text { bifida }\end{array}$ & $9: 17: 21$ & $6: 24: 17$ & $69.42 \%$ & $1: 12: 34$ & -- & -- \\
\hline DH703 & $\mathrm{F}$ & 62 & $\begin{array}{l}\text { Relatively } \\
\text { healthy }\end{array}$ & $8: 36: 21$ & $7: 31: 43$ & $87.38 \%$ & $0: 17: 09$ & 1.9 & $6.84 \%$ \\
\hline DH704 & $\mathrm{F}$ & 80 & $\begin{array}{l}\text { Relatively } \\
\text { healthy }\end{array}$ & $8: 36: 48$ & $7: 45: 00$ & $83.98 \%$ & $0: 07: 12$ & 2.3 & $3.39 \%$ \\
\hline DH705 & $\mathrm{M}$ & 72 & $\begin{array}{l}\text { Stroke } \\
\text { sufferer }\end{array}$ & $9: 35: 00$ & $8: 57: 30$ & $93.43 \%$ & $0: 02: 20$ & 3 & -- \\
\hline DH706 & $\mathrm{F}$ & 88 & $\begin{array}{l}\text { Relatively } \\
\text { healthy }\end{array}$ & $7: 50: 40$ & -- & -- & -- & 2.15 & $2.52 \%$ \\
\hline DH707 & $\mathrm{F}$ & 64 & $\begin{array}{l}\text { Relatively } \\
\text { healthy }\end{array}$ & $8: 43: 35$ & $7: 00: 20$ & $80.26 \%$ & $0: 25: 20$ & 1.92 & $8.35 \%$ \\
\hline DH708 & $\mathrm{M}$ & 81 & $\begin{array}{l}\text { Relatively } \\
\text { healthy }\end{array}$ & $8: 30: 34$ & $6: 42: 13$ & $79.11 \%$ & 0:37:09 & 2.37 & $7.79 \%$ \\
\hline DH709 & $\mathrm{F}$ & 65 & $\begin{array}{l}\text { Relatively } \\
\text { healthy }\end{array}$ & 7:10:00 & $6: 12: 56$ & $81.11 \%$ & $0: 09: 48$ & 2 & $8.47 \%$ \\
\hline DH710 & $\mathrm{F}$ & 72 & $\begin{array}{l}\text { Relatively } \\
\text { healthy }\end{array}$ & $7: 43: 00$ & 5:52:00 & $70.83 \%$ & $0: 25: 20$ & 1.71 & $11.7 \%$ \\
\hline
\end{tabular}

* indicate parameters extracted from Tactex BEDsensor ${ }^{\mathrm{TM}}$, all other parameters extracted from actigraph watch

TABle 2: MEAN SLeEp PARAMETERS

\section{Tactex BEDsensor ${ }^{\mathrm{TM}}$, Data}

No. of Hours in Bed per night

No. bed exits per night

Length Bed Exits

Hourly Epochs of Restlessness per Night

Total No. Epochs Restlessness per Night

Restlessness

$\begin{array}{lllll}\text { Mean } & \text { Std. Dev } & \begin{array}{c}\text { Actigraph } \\ \text { Watch Data }\end{array} & \text { Mean } & \text { Std. Dev } \\ 8.7417 & 0.6805 & \text { Actual sleep time } & 07: 00: 2 & 00: 56: 4 \\ 2.3654 & 0.6959 & \text { Actual sleep (\%) } & 84.4055 & 5.88208 \\ 2.8285 & 1.3145 & \text { Sleep efficiency } & 79.5194 & 8.24342 \\ 10.948 & 6.5748 & \text { Sleep latency } & 00: 27: 4 & 00: 23: 0 \\ 86.558 & 57.511 & \text { Moving mins. } & 68.8577 & 20.1942 \\ 8.51 \% & 5.15 \% & \text { Moving time }(\%) & 13.9622 & 4.33941 \\ & & \text { Restlessness } & 45.6572 & 13.0513\end{array}$


Data sources from the Tactex BEDsensor ${ }^{\mathrm{TM}}$ and actigraph watch have been compared in [14]. The results showed that on average, high specificity values (89.6\%), high sensitivity values $(69.6 \%)$ and low misclassification rates $(13.3 \%)$ were obtained using the Tactex BEDsensor ${ }^{\mathrm{TM}}$ for sleep monitoring of the elderly cohort under investigation.

\section{DAILY AND NOCTURNAL CORRELATIONS}

Theoretical models emphasize that there might be an interplay of circadian rhythms with the modern world, and that there is a social rhythm in addition to purely circadian and biological rhythms (e.g. [15] and [16]). This suggests that factors such as the work schedule, regular activities (e.g. going to the gym, having family dinners) influence and stabilize or destabilize biological rhythms, especially if there is vulnerability for unstable rhythms [17]. Ehlers et al. [15] term such factors that characterize our daily schedule and also influence biological rhythms "social zeitgebers". They argue that disruptions in the social rhythm cause a dysregulation of biological patterns that in turn can cause affective symptoms in vulnerable individuals. Whether an irregular social rhythm causes biological dysregulations itself or influences biological patterns by influencing the sleep-wake cycle, which in turn causes a biological dysregulation, is yet unclear. Using the "Social Rhythm Metric" (SRM; [18]) to quantify social daily rhythms, several studies have demonstrated an association between social rhythm disruptions and affective symptoms. The Social Rhythm Metric quantifies the stability of an individuals' daily routine. It lists 17 activities that have been identified as central in everyday life and leaves space for two more optional activities for the individual. The SRM is meant to be completed every day, with subjects writing down the exact time of the beginning of an activity. A short version of the SRM was proposed by [19], where only five activities (get out of bed, first communication, start work, have dinner, go to bed) are considered. As two of the five activities are related to sleep-wake patterns (get out of bed and go to bed), this short version of the SRM emphasizes the sleepwake cycle as a major anchor in the daily social rhythm. The SRM has been described as a valid instrument in different studies (e.g. [18], [20]). The authors of this paper proposed an augmented social index to that described by Monk et al., which encapsulates how a social activity index may be measured and used to monitor irregularities from norms or changes in daily life styles. The items monitored included, mobility through pedometers and GPS trackers, frequency and duration of both incoming and outgoing telephone calls and self reported social and described activities from audio diary events. A method was developed to score the persons activity based on the median of each sensors daily accumulated value and the range of the particular sensor device. To score the daily data, if the sensor reading fell in the normal range a score of 0 was given, if the data fell in the medium range a score of +1 or -1 was given and if the data fell in the high range a score of +2 or -2 was given. The scoring system was developed as deviations from the norm were required and not numeric representations of daily activities. The scoring system is described as a Social Routine Mobility and Activity index and describes frequency of occurrence of described activities on a daily basis.

\section{DAILY AND NOCTURNAL CORRELATIONS}

As this paper describes a preliminary study the results of the daily and nocturnal correlations are described in qualitative measures through specific case studies.

A. Case Study 1, Participant DH710 is a very social character; from her audio diaries she stated that she has numerous visits and phone calls each day. The participant's audio diaries are recalled in the dialogue below together with subjective sleep analysis. Fig. 1 and 2 show the extracted sleep parameters and Table 3 shows the numerical values obtained.

\section{Evening Diary:}

Friday 6th: "When I woke today I wasn't too good. I had a bit of a pain in the head but that went away. I didn't take any medication for it but feels much better now. It was a good day"

Friday $6^{\text {th }}$ had the second highest measurement in the SRMA Index. Even though she did not feel great on awakening, she had a very active day and reported that it was a good day in the evening

Does an active social day help to improve mood?

Objective sleep analysis shows it was her second worse nights sleep (see Fig 1). Deteriorating sleep quality (compared to normal) resulted in declining and negative mood states but did not seem to affect the participants' social and daily routines within short term periods.

\section{Morning Diaries \& Subjective Sleep Monitoring}

Thurs. 5th: "I slept the same as usual (4 out of 5), I went to bed at 1 a.m. and got up once during the night. I woke at 8a.m. and dozed again and got up at 10a.m."

Fri. 6th: "I didn't sleep well (3 out of 5), I went to bed at 2, got up several times to go to the toilet. I woke up at 7.30a.m. and got up at 11a.m. I was in a lot of pain during the night."

Sat 7th: "I went to bed at 3.30a.m. I did a lot of tossing and turning for a while. I woke 2-3 times; I got up to look for my alarm pendent and went to the toilet. I woke at 7.30 - 8.30a.m. I got up at 11a.m. It was a bad night's sleep"

Sun 8th: "I slept good it was a 4 (out of 5), I went to bed at 1.30a.m. and got up at 10a.m."

Mon 9th: "I slept good, I went to the toilet twice, got up at 10.30a.m."

Tues $10^{\text {th }}$ :-

Wed $11^{\text {th }}$ : "I slept fairly good went to toilet once, got up after 10a.m."

The consistencies between subjective and objective sleep quality may be clearly seen for Friday and Saturday nights, which also correspond to the self reported negative state of mind, "I didn't feel great this morning" but does not seem to have any correlation to daily activities as seen from the SRMA scale (Fig. 3). An irregular nights' sleep is clearly visible through actigraphy and restlessness monitoring. 


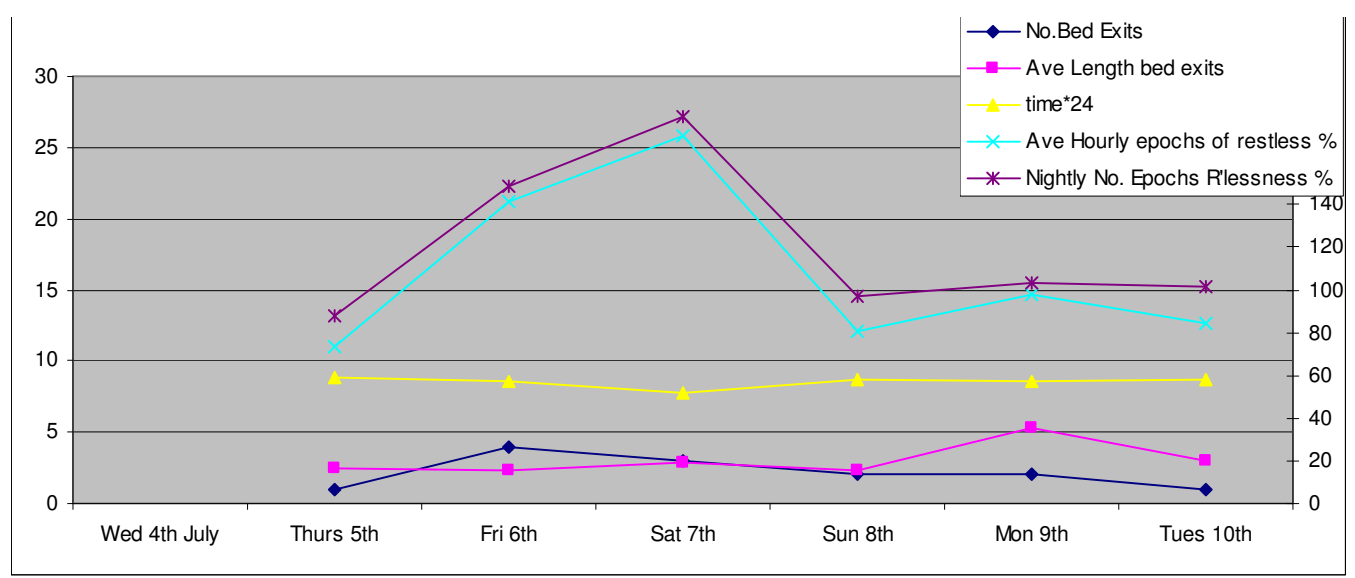

Fig 1: Objective Sleep Summary for participant DH710 A "bad" night's sleep is observed on Friday 6th and Saturday 7th.

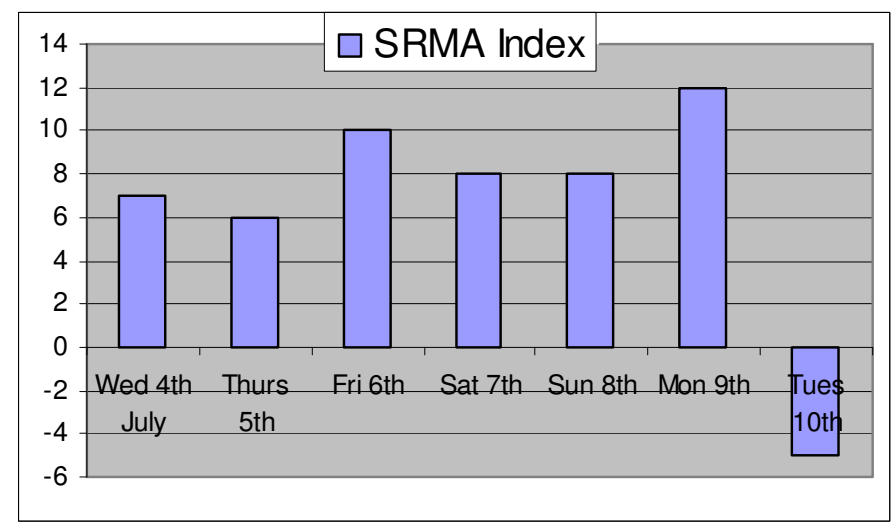

Fig 2: SRMA index for participant DH710 (Sensors were removed on Tues. $10^{\text {th }}$ )

TABLE 3: OBJECTIVE SLEEP PARAMETERS SHOWING CLEARING THE INCREASED RESTLESSNESS ON THE SUBJECTIVELY PERCEIVED BAD NIGHTS SLEEP

$\begin{array}{lllllllll} & \begin{array}{c}\text { Get Up } \\ \text { time }\end{array} & \begin{array}{c}\text { Bed } \\ \text { time }\end{array} & \begin{array}{c}\text { No. } \\ \text { Bed Exits }\end{array} & \begin{array}{c}\text { Length } \\ \text { bed exits }\end{array} & \begin{array}{c}\text { Time } \\ \text { bed }\end{array} & \begin{array}{c}\text { Ave. } \\ \text { Hourly } \\ \text { Restl'ness }\end{array} & \begin{array}{c}\text { Total } \\ \text { Restl'ness }\end{array} & \text { nightly } \\ \text { Wed 4th } & & 01: 22: 29 & & & & & & \\ \text { Thurs 5th } & 10: 12: 28 & 02: 12: 59 & 1 & 2.5 & 8.833056 & 11 & 8.44 \% & 88 \\ \text { Fri 6th } & 10: 47: 25 & 03: 20: 59 & 4 & 2.25 & 8.573889 & 21.14 & 14.63 \% & 148 \\ \text { Sat 7th } & 11: 08: 28 & 01: 38: 24 & 3 & 2.8 & 7.791389 & 25.85 & 19.69 \% & 181 \\ \text { Sun 8th } & 10: 16: 56 & 02: 01: 59 & 2 & 2.25 & 8.642222 & 12.125 & 9.51 \% & 97 \\ \text { Mon 9th } & 10: 36: 56 & 02: 20: 55 & 2 & 5.25 & 8.5825 & 14.7 & 10.17 \% & 103 \\ \text { Tues10th } & 11: 00: 29 & 01: 48: 24 & 1 & 3 & 8.659444 & 12.6 & 9.88 \% & 101 \\ \text { Wed 11th } & 09: 58: 27 & 02: 49: 53 & 2 & 3 & 8.1675 & 13.4 & 8.44 \% & 94\end{array}$

\section{B. Case Study 2}

A disturbance in participant DH703s' sleep is clearly evident on Wednesday $13^{\text {th }}$ (see Fig. 4). Increased actigraph and Tactex BEDsensor ${ }^{\mathrm{TM}}$ restlessness parameters within the sleeping pattern may be seen. As in the previous example, this was identified in the self reported diary "I slept bad last night (rated as 2 out of 5, I went to bed at around 11p.m. and was still awake at 2 a.m. this morning" but does not seem to effect the social and daily activities of the individual as may be seen in the SRMA scale in Fig 3. Table 4 below shows the distinctions and comparisons between subjective and objective data accounts. A strong correlation between subjective and objective data sets are present for this participant.

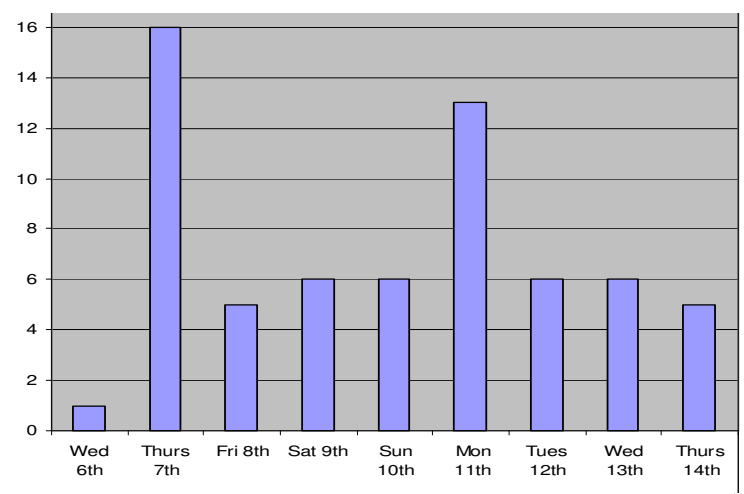

Fig. 3:Participant DH703 SRMA Index (sensors installed on Wed. $6^{\text {th }}$ ) 


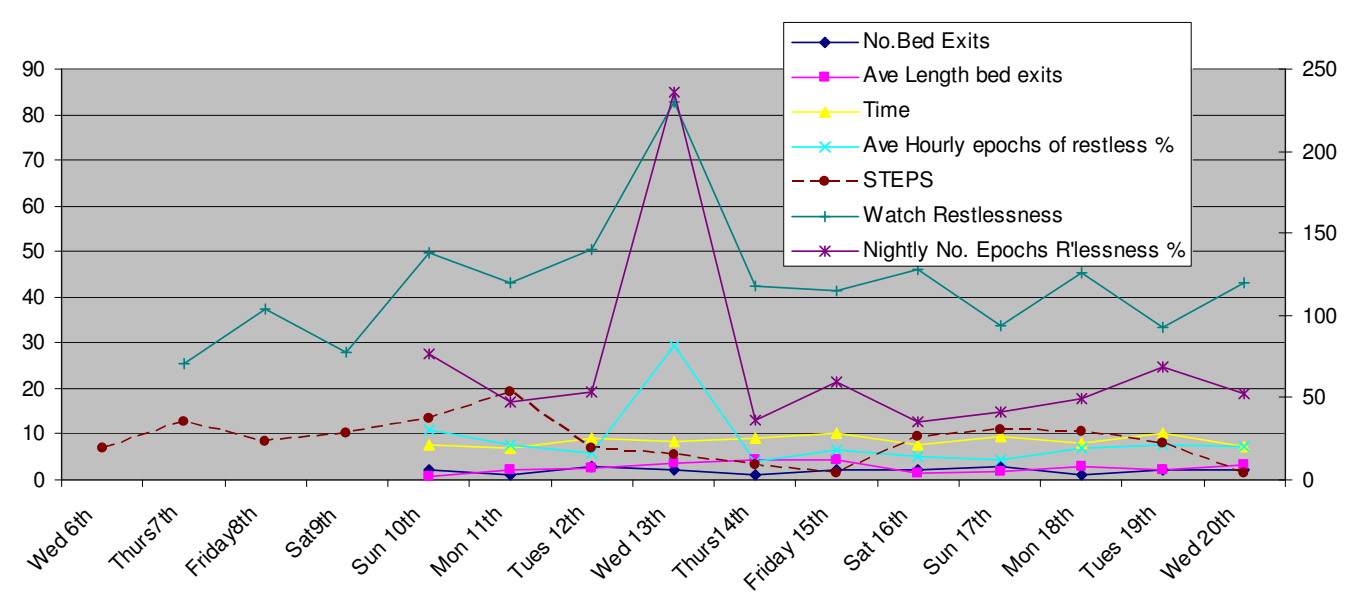

Fig. 4: Participant DH703 Sleep analysis

\begin{tabular}{|c|c|c|}
\hline Day & Subjective & Objective \\
\hline \multirow[t]{3}{*}{ 10th } & $\begin{array}{l}\text { M: = Morning Diary, E: = Evening Diary } \\
\text { M: "I had a poor nights sleep (rates as 3)" }\end{array}$ & $\begin{array}{c}\text { Restless } 8.6 \% \text { (her second } \\
\text { worse night) }\end{array}$ \\
\hline & $\begin{array}{l}\text { M: "I went to bed at 12.30a.m., it took me a long time to fall } \\
\text { asleep I was still awake at 3a.m." }\end{array}$ & Went to bed at 00:37 \\
\hline & M: "I got up once" & Got up twice \\
\hline \multirow[t]{5}{*}{$11^{\text {th }}$} & $\begin{array}{l}\text { M: "I slept well last night (rated as 4); I went to bed at } \\
\text { 11.40p.m." }\end{array}$ & Went to bed at 23:52 \\
\hline & M: "I fell asleep very quickly (rated 4)" & \\
\hline & M: "I went to bathroom once" & Got up once \\
\hline & M: "I got up early, at about 6.50am" & Got up at $6: 47: 20$ \\
\hline & $\begin{array}{l}\text { M: "I have a busy day ahead, I have to go to the hospital but } \\
\text { I expect that it will be ok because I feel good. I have a busy day } \\
\text { ahead" }\end{array}$ & $\begin{array}{l}\text { Restless is } 5.72 \% \text { which is } \\
\text { below mean. }\end{array}$ \\
\hline \multirow[t]{4}{*}{12 th } & M: “I slept well (rated 4)" & \\
\hline & $\begin{array}{l}\text { M: "I don't remember the time I went to bed but I fell asleep } \\
\text { quickly" }\end{array}$ & Went to bed at 23:55 \\
\hline & M: "I was up twice last night and was restless this morning" & $\begin{array}{l}\text { Got up three times during } \\
\text { night and got up at 9:09. Restless } \\
\text { hour between } 5 \text { and 6a.m. }\end{array}$ \\
\hline & $\begin{array}{l}\text { M: "I felt grumpy and tired, I probably overdid it yesterday" } \\
\text { (High SRMA for } 11^{\text {th }} \text {, due to hospital trip and linked activities) }\end{array}$ & $\begin{array}{l}\text { Restlessness is } 4.83 \% \text {, spent } \\
9.13 \text { hours in bed }\end{array}$ \\
\hline \multirow[t]{4}{*}{ 13th } & $\begin{array}{l}\text { M: "I slept bad last night (rated as 2, I went to bed at around } \\
\text { 1p.m.1 and was still awake at 2a.m. this morning" }\end{array}$ & $\begin{array}{l}\text { Went to bed at 22:48. Restless } \\
\text { index } 23.35 \% \text { (very high) }\end{array}$ \\
\hline & $\begin{array}{l}\text { M: "I tried reading and watching tv" } \\
\mathrm{E}:\left(12^{\mathrm{TH}}\right) \text { :On day before Participant did a lot of gardening and } \\
\text { was happy with progress but had intended to work on a legal } \\
\text { case for solicitor (indication of worry and stress) }\end{array}$ & \\
\hline & $\begin{array}{l}\text { M: “I was up several times during the night, I've forgotten } \\
\text { how many" } \\
\mathrm{E}(12 \mathrm{TH}) \text { :When asked about mood the night before "my mood } \\
\text { was good all day. It's not too good now because I didn't do the } \\
\text { writing which I should have done and I haven't for any } \\
\text { housework done. I am just shattered now! }\end{array}$ & $\begin{array}{l}\text { Only got up twice, but average } \\
\text { length of bed exits was } 3.75 \mathrm{mis}\end{array}$ \\
\hline & $\begin{array}{l}\text { M: "I woke up normally but I need to tidy for the engineer" } \\
\text { M: "I don't have any other plans I'll just take it as it comes } \\
\text { that is if I have any energy after the bad night!" } \\
\text { E(13TH):On evening diary "The low points were that I didn't } \\
\text { feel on top of the world today" }\end{array}$ & $\begin{array}{l}\text { Got up at } 7: 18 \text {, spent } 8.49 \mathrm{hrs} \\
\text { in bed }\end{array}$ \\
\hline $14^{\text {th }}$ & $\begin{array}{l}\mathrm{M} \text { : "I slept well last night (rates at 4) I went to bed at } \\
\text { 11.30pm and slept very quickly, woke at 7a.m., but slept again } \\
\text { until 9.05am" }\end{array}$ & $\begin{array}{l}\text { Went to bed at } 00: 03 \text { Got up at } \\
9.04 \text {, got up once during the } \\
\text { night. Average restlessness of } \\
3.36 \%\end{array}$ \\
\hline
\end{tabular}




\section{CONCLUSION}

Initial results have shown that the participants sleeping patterns were quite consistent, but disturbances are clearly identifiable and may be linked to specific instances such as pain, anxiety and fear. The appearances of short disturbances (1-2 nights in duration) within a regular sleeping pattern do not seem to disrupt the daily social rhythm but are identified through self reports. Significant inter-night and intra-subject variability is noted in sleep studies, so longer term trending analysis needs to be established to determine a person's base line behaviour and sleeping pattern. The regularity of sleeping patterns displayed by participants in this study may be due to their general health, as the participants are individuals who are successfully living independently. Those with greater health problems, which are associated with deteriorating sleep patterns, should be expected to have a diminished competence for self-sufficient living and be more likely to move in with family members for assisted care [3]

Duncan et al. [21] suggested that community living elderly were more regular in their life-style behaviours than a control group of younger persons. It is possible that such consistency in their daily schedules may be functional by facilitating the preservation of sleep patterns that the ageing process and physical problems can disrupt [3]

\section{REFERENCES}

[1] D. Foley et al., Sleep Complaints among elderly persons: an epidemiologic study of three communities. Sleep. 18: p. 425-432, (1995).

[2] S.F. Quan and P. Zee, Evaluating the effects of medical disorders on sleep in the older patient. Geriatrics. 59: p. 37-42, (2004).

[3] E.B. Thoman, C. Acebo and S. Lamm, Stability and Instability of Sleep in Older Persons Recorded in the Home. Sleep. 16(6): p. 578-585, (1993).

[4] C.A. Czeisler, et al., Association of sleep-wake habits in older people with changes in output of circadian pacemaker. . Lancet. 340(8825): p. 933-936, (1992).

[5] D. Foley, S. Ancoli-Israel, P. Britz and J. Walsh, Sleep Disturbances and Chronic Disease in Older Adults: results of the 2003 National Sleep Foundation Sleep in America Survey. J. Psychosom. Res. 56: p. 497-502, (2004).

[6] M. Ohayon, J. Zulley, C. Guilleminault, S. Smirne, and R.G. Priest, How age and daytime activities are related to insomnia in the general population: consequences for older people. Journal of the American Geriatric Society. 49(4): p. 360-366, (2001).

[7] N.S Gooneratne, et al., Functional Outcomes of excessive daytime sleepiness in older adults. J. Am. Geriatr. Soc. 51: p. 642-649, (2003).

[8] E.R. Chasens, S.M. Sereika, T.E. Weaver, and M.G. Umlauf, Daytime Sleepiness, Exercise, and Physical Function in Older Adults. Sleep Res. 16: p. 60-65, (2007).

[9] T.H. Monk, Circadian Rhythm. Clin Ger Med. 5: p. 331-346, (1989).

[10] S. Benloucif, et al., Morning or Evening Activity Improves Neuropsychological Performance and Subjective Sleep Quality in Older Adults. Sleep. 27(8): p. 1542-1551, (2005).

[11] A. Shirota, M. Tamaki, H. Nittono, M. Hayashi, and T. Hori, Volitional Lifestyle and Nocturnal Sleep in the Healthy Elderly' Sleep Research Online. 4(3): p. 91-96, (2001).

[12] T.H. Monk, C.F. Reynolds III, M.A. Machen, and D.J. Kupfer, Daily Social Rhythms in the Elderly and Their Relation to Objectively Recorded Sleep. American Sleep Disorders Association and Sleep Research Society. 15(4): p. 322-329, (1992).
[13] J. Hislop, S. Arber, R. Meadows, and S. Venn, Narratives of the Night: The use of audio diaries in researching sleep. Sociological Research Online. 10(4), (2005).

[14] L. Walsh, S. McLoone, J. Behan, and T. Dishongh, The Deployment of a Non-Intrusive Alternative to Sleep/Wake Wrist Actigraphy in a Home-Based Study of the Elderly (submitted for publication), in EMBC'08. 2008: Vancouver, British Columbia, Canada.

[15] C. Ehlers, E. Frank, and D.J. Kupfer, Social zeitgebers and biological rhythms. Archives of General Psychiatry. 45: p. 948952, (1988).

[16] E. Frank, Treating Bipolar Disorder, A Clinician's Guide to Interpersonal and Social Rhythm Therapy. 2005, New York: Guilford Press.

[17] D. Meyer Thomas and Maier Silke, Is there evidence for social rhythm instability in people at risk for affective disorders? Psychiatry Research. 141(1): p. 103-114, (2006).

[18] T.H. Monk, J.F. Flaherty, E. Frank, K. Hoskinson, and D.J. Kupfer. The Social Rhythm Metric. An instrument to quantify the daily rhythms of life. Journal of Nervous and Mental Disease. 178: p. 120-126, (1990).

[19] T.H. Monk, E. Frank, J.M. Potts, and D.J. Kupfer, A simple way to measure lifestyle regularity. Journal of Sleep Research. 11: p. 183-190, (2002).

[20] E. Frank, et al., Interpersonal and social rhythm therapy for bipolar disorder: integrating interpersonal and behavioural approaches. Behaviour Therapist. 17: p. 143-149, (1994).

[21] J.C. Gillin, W.C. Duncan, and D.L. Murphy, Age-Related Changes in Sleep in Depressed and Normal Subjects. Psychiatry Res. 4: p. 73-78, (1981). 